\title{
Silver-modified titania with enhanced photocatalytic and antimicrobial properties under UV and visible light irradiation
}

E. Kowalska ${ }^{\text {a, }}$, Z. Wei ${ }^{\text {a }}$, B. Karabiyik ${ }^{\text {a }}$, A. Herissan ${ }^{\text {b }}$, M. Janczarek ${ }^{\text {a,c }}$, M. Endo ${ }^{\text {a }}$, A. Markowska-Szczupak ${ }^{\mathrm{a}, \mathrm{d},{ }^{*}, \text { H. Remita }}{ }^{\mathrm{b}}, \mathrm{B}$. Ohtani $^{\mathrm{a}}$

${ }^{a}$ Catalysis Research Center, Hokkaido University, N21, W10, 001-0021 Sapporo, Japan

${ }^{\mathrm{b}}$ Laboratoire de Chimie Physique, Université de Paris-Sud, Bâtiment 349, 91405 Orsay, France

${ }^{\mathrm{c}}$ Department of Chemical Technology, Gdansk University of Technology, ul. Narutowicza 11/12, 80-233 Gdansk, Poland

${ }^{\mathrm{d}}$ Institute of Chemical and Environmental Engineering, West Pomeranian University of Technology, ul. Pulaskiego 10, 70-322 Szczecin, Poland

* Corresponding authors. Tel.: +81 117069130,

E-mail address: kowalska@cat.hokudai.ac.jp (E. Kowalska);

Tel.: +48 914494230

E-mail address: agata@erb.pl (A. Markowska-Szczupak)

\begin{abstract}
Commercial titania photocatalysts were modified with $2 \mathrm{wt} \%$ of silver by photodeposition. The properties of the samples were characterized by DRS, XPS, XRD, FE-SEM and STEM. The modified samples exhibited activity under visible light and enhanced activity under UV irradiation for 2-propanol and acetic acid oxidation, respectively. The time-resolved microwave conductivity (TRMC) analysis indicated that enhanced activity (2.5-8-fold enhancement depending on titania) under UV irradiation was caused by an electron storage in metallic nanoparticles (NPs), and therefore decreasing the recombination between charge carriers. The action spectrum (AS) analysis proved that localized surface plasmon resonance (LSPR) of silver NPs induced the photocatalytic activity under visible light irradiation. The increase of antimicrobial properties under visible light irradiation indicated that not only intrinsic properties of silver in the dark, but also plasmonic properties of $\mathrm{Ag} @ \mathrm{TiO}_{2}$ were responsible for overall bacteria killing. The evolution of carbon dioxide under both irradiation ranges indicated mineralization of bacteria cells, and therefore possible application of silver-modified titania for decomposition of chemical and biological pollutants.
\end{abstract}

\section{Keywords}

Plasmonic photocatalysts, Silver nanoparticles, Action spectra, Time-resolved microwave conductivity, Antimicrobial properties,

\section{Introduction}


During the past forty years titanium(IV) oxide (titania, $\mathrm{TiO}_{2}$ ) has been widely investigated for its high photocatalytic activity, redox properties, thermal and chemical stability and non-toxicity [1]. The limitation in its application, resulting from low quantum yield (fast recombination of charge carriers: $\mathrm{e}^{-} / \mathrm{h}^{+}$) and necessity to use UV irradiation, may be overcome since modified titania often possess higher level of activity and ability of working under visible light. Preparation of pure titania with narrower bangap [2-5] and application of huge variety of organic and inorganic compounds as dopants or surface modifiers have been widely examined [6-8]; among them noble metals, since they enhance the transfer of photogenerated electrons prolonging charge carriers lifetime [9]. Some of them, exhibiting plasmonic properties (localized surface plasmon resonance, LSPR) at the visible range, such as gold and silver, may also activate wide band gap semiconductors $\left(\mathrm{TiO}_{2}, \mathrm{CeO}_{2}\right)$ towards visible light $[10,11]$. It was proved that LSPR was responsible for activity of $\mathrm{Au} @ \mathrm{TiO}_{2}$, due to resemblance between action and absorption spectra [12]. It was also proposed that a broad size and shape distribution of metallic nanoparticles (NPs), on the contrary to dark activity of nanosized gold [13], and thus ability of photon absorption at broad wavelength range, was responsible for high level of photocatalytic activity. Though, the activity of gold-modified titania was proved, the quantum yield of reactions under visible light is low and should be improved [14]. In addition, the high cost of gold limits application of $\mathrm{Au} @ \mathrm{TiO}_{2}$. Thus, silver-modified titania seems more promising for decomposition of both chemical and biological pollutants. Antimicrobial properties of silver and copper have been used since ancient times. Presently, their bactericidal properties are commonly used by application of silver and copper in the form of NPs or nano-films [15].

The enhancement of antimicrobial properties of titania modified with noble metals under irradiation is expected, due to possible synergism between dark antimicrobial properties of noble metals and photo-disinfection properties of photocatalyst, since reactive oxygen species (ROS) are generated on the surface of irradiated semiconductor $[16,17]$. The possible 
additional antimicrobial properties originated from plasmonic heating may enhance final disinfection effect. Thus, effective systems for cleaning of air, water/wastewater and surfaces can be designed.

Here, we are presenting our data showing properties and activities of silver-modified titania photocatalysts and their possible application for decomposition of methanol, acetic acid, 2-propanol and Escherichia coli.

\section{Material and methods}

$2 \mathrm{wt} \%$ of silver was deposited on the surface of eight commercial titania samples of various surface properties and crystalline forms (anatase: ST-01, ST-41, TIO-10, and rutile: ST-G1, Ald_R, UFR, TIO-5, TIO-6; details are shown in Supplementary Information in Tables s2 and s4). $\mathrm{TiO}_{2}$-samples were suspended in $50 \mathrm{vol} \%$ aqueous methanol or 2-propanol (alcohols were used as hole scavenger), an aqueous solution of $\mathrm{AgNO}_{3}$ was added and oxygen was removed by argon bubbling. The suspensions were UV-irradiated with $400 \mathrm{~W}$ mercury lamp, in the system described previously [14], for $1 \mathrm{~h}$ at $298 \mathrm{~K}$ with magnetic stirring. Liberated hydrogen from methanol or 2-propanol suspensions, were measured by gas chromatography. The $\mathrm{Ag} @ \mathrm{TiO}_{2}$ powders were centrifuged, washed three times with methanol and then at least three times with water, dried at $120^{\circ} \mathrm{C}$ overnight and grinded.

The photocatalysts were characterized by diffuse reflectance spectroscopy (DRS), field-emission scanning electron microscopy (FE-SEM), scanning transmission electron microscopy (STEM), X-ray powder crystallography (XRD), and X-ray photoelectron spectroscopy (XPS). DRS spectra were taken for solid and suspended (under magnetic stirring) photocatalysts.

The charge-carrier lifetimes in $\mathrm{TiO}_{2}$ after UV illumination $(355 \mathrm{~nm})$ were determined by microwave absorption experiments using the time-resolved microwave conductivity method (TRMC) [18]. 
The photocatalytic activity was measured for decomposition of acetic acid and 2-propanol ( $5 \mathrm{vol} \%)$ on five bare and silver-modified $\mathrm{TiO}_{2}$ samples. Generated carbon dioxide and acetone were analyzed chromatographically. The photoactivity was checked under visible and UV/vis irradiation using xenon lamp equipped with Y48 cut-off filter $(\lambda>450 \mathrm{~nm})$ and a mercury lamp, respectively. The action spectrum measurements were carried out using a diffraction grating type illuminator equipped with a $300 \mathrm{~W}$ xenon lamp.

Antimicrobial properties were examined in the dark and during irradiation with UV and/or visible light for seven $\mathrm{Ag} @ \mathrm{TiO}_{2}$ photocatalysts (Table s4) by two methods:

i) the method of small paper disc (Whatman paper, $\phi=1 \mathrm{~cm}$ ), i.e., discs were saturated with photocatalyst ( $1 \mathrm{~g} / \mathrm{L})$, placed on Petri dishes to which bacteria solution ( $1 \mathrm{~g} / \mathrm{L}$, Escherichia coli, which corresponds to $1.5 \times 10^{8}$ bacteria in $1 \mathrm{~mL}$ of solution) was spread, and inhibition zones around discs were measured.

ii) the method of suspension, i.e., $5 \mathrm{~mL}$ of bacteria suspension (the same concentration as shown above) was added to photocatalysts $(50 \mathrm{mg})$. The suspension was continuously stirred and irradiated. $0.5 \mathrm{~mL}$ of suspension was taken after $0.5,1,2,3$ hours of irradiation. The serial dilutions were prepared and $300 \mu \mathrm{L}$ of diluted suspension was spread on PCA Agar media and incubated for 24 hours at $310.8 \mathrm{~K}$. The loss of viability was examined by the viable count of the colony forming units on the plates $(\log \mathrm{CFU} / \mathrm{mL})$. The possibility of mineralization of bacteria cells was measured by determination of liberated carbon dioxide from irradiated (or dark) tubes.

Details of preparation, characterization and activity tests of obtained products are shown in Supplementary Information.

\section{Results and Discussion}

\subsection{Photocatalyst preparation}

Data for hydrogen evolution during silver deposition on titania surfaces are shown in Fig. 1. For comparison, hydrogen evolution on gold-modified titania: ST-01 was also presented 
in the left part of Fig. 1 (data reported before [14]). The induction period, necessary time for reduction of metal cations $\left(\mathrm{Au}^{3+}, \mathrm{Ag}^{+}\right)$and formation of metallic NPs, was much longer in the case of silver than gold NPs and at least 45 minutes of irradiation was necessary for silver NPs formation, while only a few minutes was sufficient to form gold NPs (linear evolution of hydrogen shown as dashed line in the left part of Fig. 1). Silver-modified titania possesses much lower activity for methanol dehydrogenation than gold ones (ca. 20 times). Similar results have been reported for gold-, silver- and platinum-modified titania, and the highest activity of platinum-modified titania originated from its highest work function, i.e. 5.93, 5.31 and $4.74 \mathrm{eV}$ for $\{111\}$ crystallite planes of $\mathrm{Pt}, \mathrm{Au}$ and $\mathrm{Ag}$, respectively $[19,20]$. The greater is the difference between the metal work function and that of titania, the higher is the electronic potential barrier (Schottky barrier) generated by the band alignment at the metal-semiconductor heterojunction, increasing the transfer and trapping of photogenerated electrons by the metal [21], and thus causing a higher hydrogen generation rate. It must be pointed that the presence of a noble metal as co-catalyst is necessary for alcohol dehydrogenation $[22,23]$. Recently, the possibility of alcohol dehydrogenation by complexes of noble metals has been reported [24, $25]$.
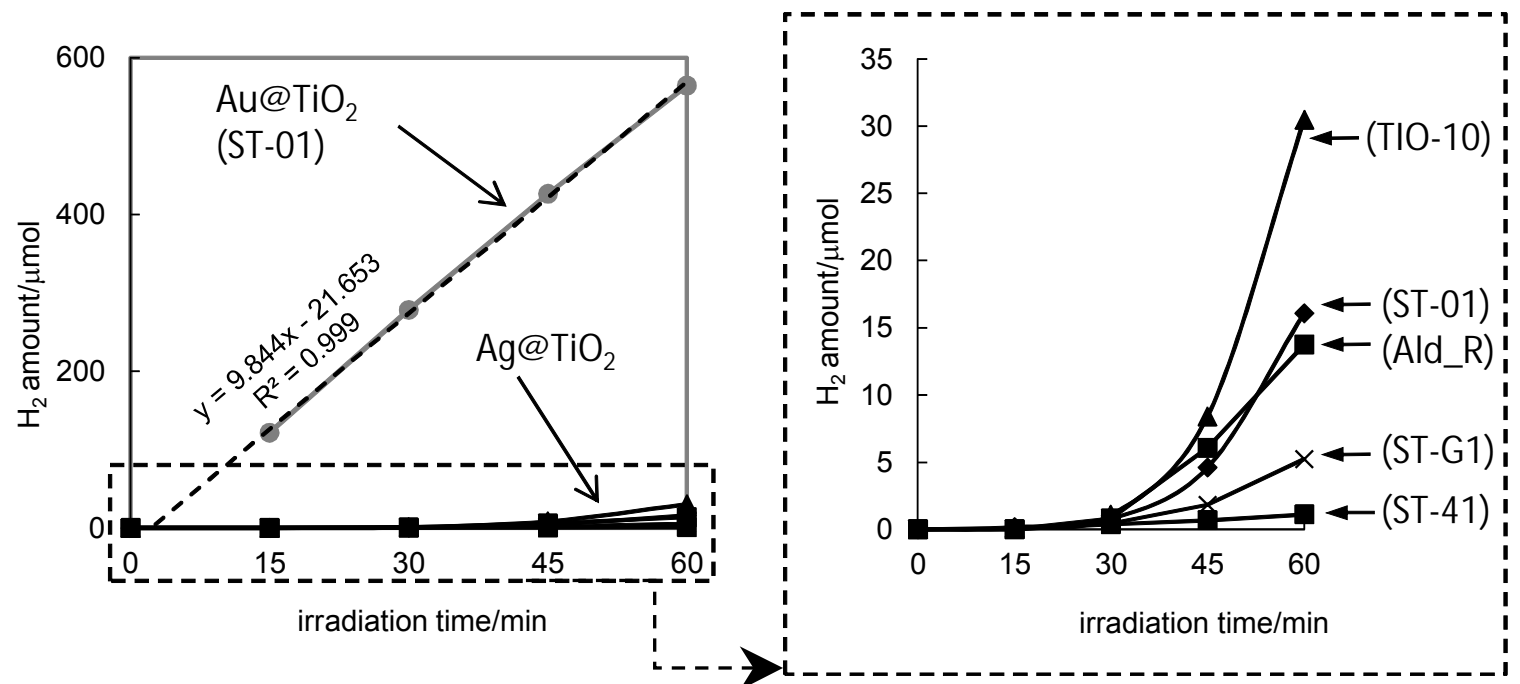

Fig. 1. left) Comparison of photocatalytic activities of Ag-modified and Au-modified titania during metal photodeposition; right) Enlargement of photocatalytic activities of silver-modified titanias. 
During irradiation, the color of titania suspension changed from white to brown or violet, due to silver NPs formation, as shown in Table s2 (Supplementary Information). The maxima LSPR values for small anatase titanias were observed at $430 \mathrm{~nm}$, while for large anatase/rutile titanias at $440 \mathrm{~nm}$, indicating that larger silver NPs were formed on larger titanias. The influence of support on metal NPs formation was also observed previously, e.g. larger silver NPs were formed on larger polystyrene globules [26], and a linear increase of mean gold NPs size with increase of particle size of support was observed during gold photodeposition on titania [14]. It is thought, that similar to gold deposition on titania, silver is preferably deposited on surface defects [27], and thus larger amount of surface defects on titania with large surface area (small NPs, [28]) caused formation of a large amount of small silver NPs.

In contrast with $\mathrm{Au} @ \mathrm{TiO}_{2}$ photocatalysts, the color of $\mathrm{Ag} @ \mathrm{TiO}_{2}$ samples was unstable and changed after drying (Supplementary Information, Table s2), probably due to partial oxidation of silver. XPS data confirmed that surface of silver NP was mainly positively charged $(>80 \%)$, as shown in Table s3 and Fig. s1 (Supplementary Information,). Fortunately, during subsequent irradiation the plasmonic properties returned to original ones, e.g., during acetic acid oxidation under visible light irradiation, as shown in the right part of Fig. 2 and Table s2. It must be pointed that color change did not influence the properties, and linear evolution of $\mathrm{CO}_{2}$ during acetic acid decomposition was observed from the beginning of irradiation (without induction period, Fig. 2, right). 

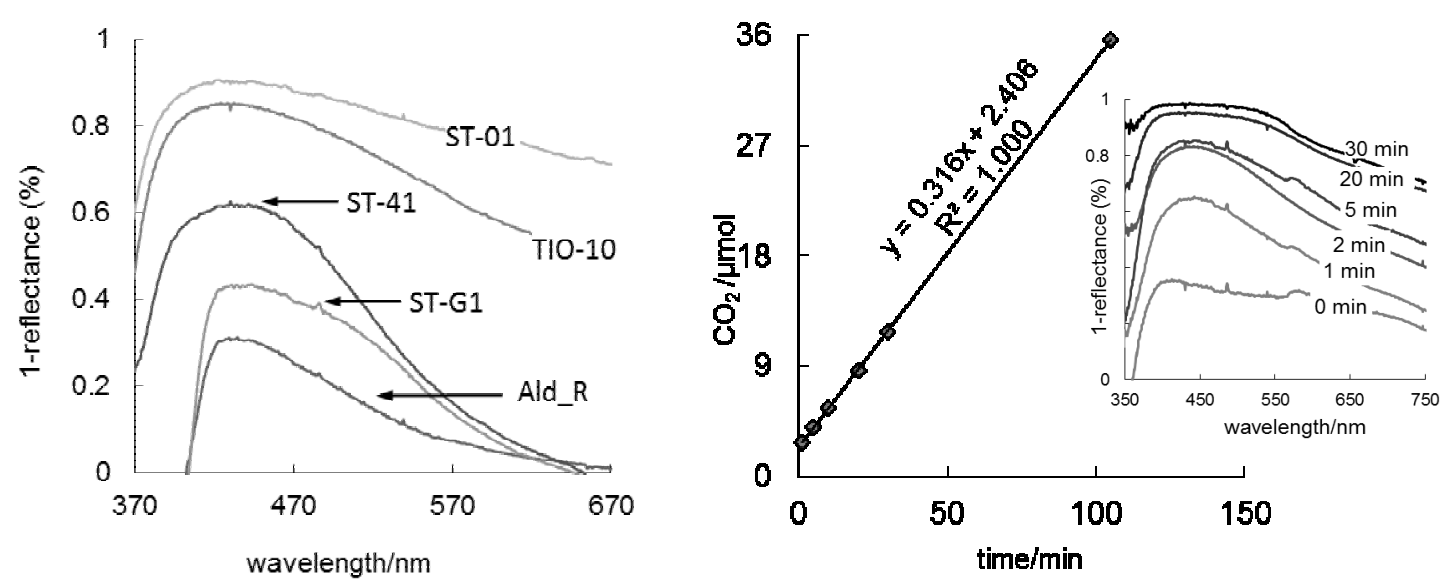

Fig. 2 left) Absorption spectra (DRS) of $\mathrm{Ag} @ \mathrm{TiO}_{2}$ taken directly after silver photodeposition (for suspended photocatalyst in methanol (50 vol\%), before sample washing and drying); right) Photocatalytic decomposition of acetic acid (5 vol\%) under visible light irradiation on $\mathrm{Ag} @ \mathrm{TiO}_{2}(\mathrm{ST}-01)$ with corresponding DRS spectra (after preparation sample was washed, dried, suspended in acetic acid and irradiated).

\subsection{Photocatalyst characterization}

The sizes of crystallites and crystalline composition were determined by XRD analysis. The exemplary XRD patterns are shown in Fig. s2. Three photocatalysts, i.e., ST-41, ST-01 and TIO10, consisted mainly anatase phase, while ST-G1 and Ald_R contained rutile phase. The crystalline sizes of titania are summarized in Tables s2. XRD analysis proved the deposition of silver crystallites on titania, and sizes of silver NPs were similar for large anatase (ST-41) and rutile (ST-G1) samples, i.e., 40 and $38 \mathrm{~nm}$, respectively.

Atomic composition and chemical characters of elements incorporated in the surface layer of modified titania were investigated by XPS analysis. The presence of silver was confirmed in all tested samples, and its amount exceeded that which was used for photodeposition, reaching 13 and $4 \mathrm{wt} \%$ for silver-modified titania ST-41 and ST-G1, respectively. It is known that deposition of metal NPs resulted in their enrichment on the surfaces [29, 30]. A much larger amount of silver might indicate the presence of extremely fine (nano-sized) silver NPs in the case of $\mathrm{Ag} @ \mathrm{TiO}_{2}(\mathrm{ST}-41)$. XPS analysis of Ag 3d showed the presence of three components attributed to $\mathrm{Ag}^{0}(368.1 \mathrm{eV}), \mathrm{Ag}^{+}\left(\mathrm{Ag}_{2} \mathrm{O}, 367.3 \mathrm{eV}\right)$ and $\mathrm{Ag}^{2+}(\mathrm{AgO}, 366.1 \mathrm{eV})$ [29]. Surface silver was mainly in an oxidized form $\left(82-89 \%, \mathrm{Ag}^{+}\right)$as shown in Supplementary Information (Fig. s2 and Table s3).

Microscopic observation confirmed the existence of silver NPs of various sizes and shapes, 
as well as rod-like NPs, as shown in Fig. 3. In the case of large rutile (ST-G1, crystalline size: $250 \mathrm{~nm}$ ) much broader distribution of silver size/shapes was detected, i.e., from nano-sized to $100 \mathrm{~nm}$ (Fig. 3, top), than for large anatase (ST-41, crystalline size: $208 \mathrm{~nm}$ ). For large anatase the NPs of silver were more uniform appearing mainly in the sizes from 10 to $40 \mathrm{~nm}$, similarly to results obtained from XRD analysis. On the other hand, small silver NPs were formed on fine titania. It is thought that similar to gold-modified titania metal NPs were mainly formed on crystalline defects [27] and that fine particles of titania possessing a large amount of such defects [31] caused formation of fine metallic NPs. While, large metallic NPs were formed on the surface of well-crystallized rutile titania with large NPs. It must be mentioned that in the case of silver deposition a large amount of nano-sized particles (1-3 nm) was easily detected (Fig. 3, top).
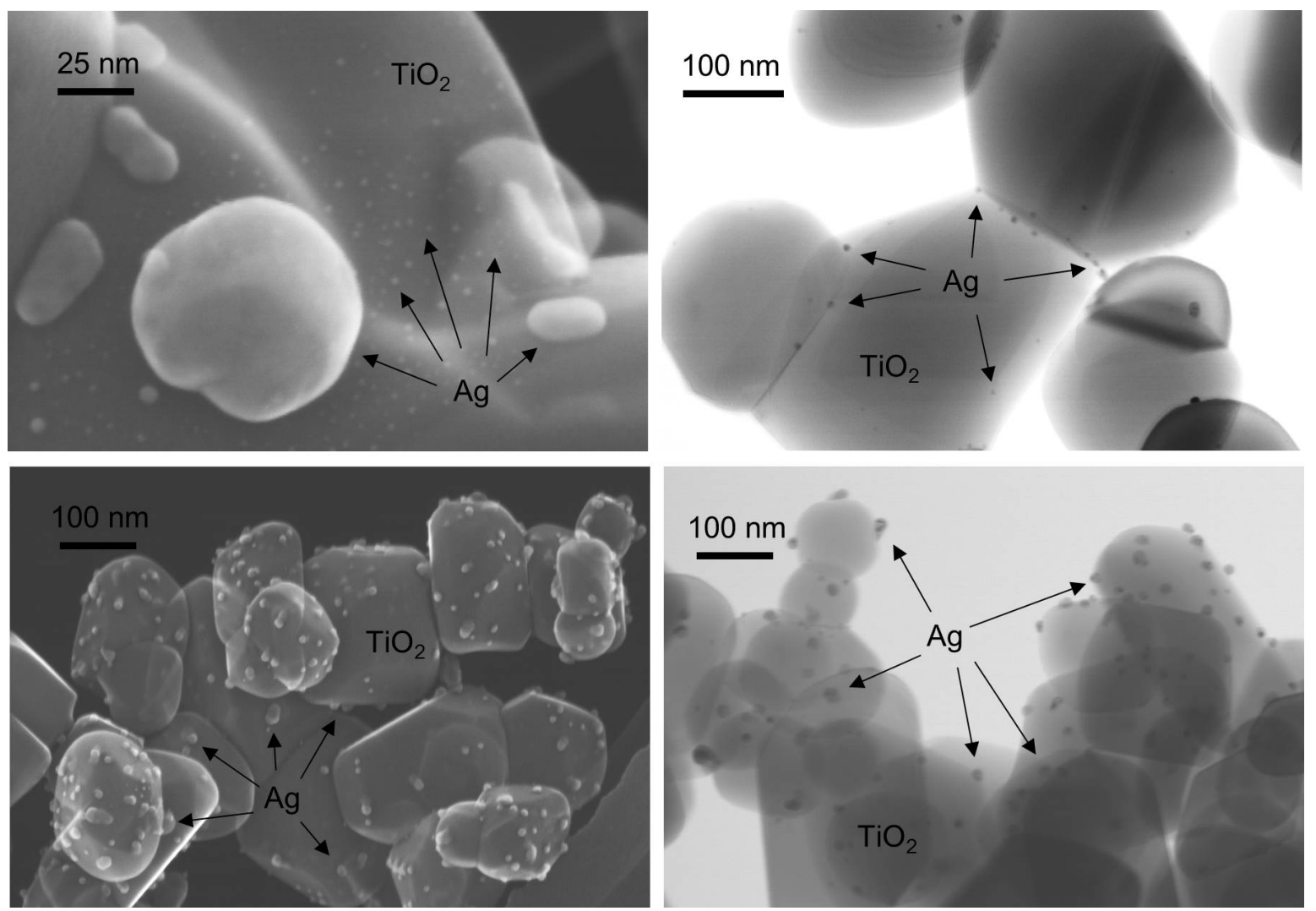

Fig. 3 STEM images of silver-modified titania: ST-G1 (top) and ST-41 (bottom).

\subsection{Photocatalytic activities under UV and/or visible light irradiation}

The activities of $\mathrm{Ag} @ \mathrm{TiO}_{2}$ photocatalysts during acetic acid and 2-propanol oxidation 
under UV and visible light irradiation are shown in Figs. 4 and 5, respectively, in comparison with previously reported data for gold-modified titanias [14].

Under UV/vis irradiation all modified photocatalysts exhibited much higher photocatalytic activities than those of corresponding bare titanias. Interestingly, the highest photoactivity for acetic acid oxidation showed $\mathrm{Ag} @ \mathrm{TiO}_{2}(\mathrm{ST}-41)$ sample of large anatase particles which showed the lowest photoactivity for methanol dehydrogenation among all modified samples (Fig. 1, right). The highest enhancement of photocatalytic activity (ca. 3.5, 4 and 7 times) was observed for Ag-modified titania with large crystallites $\left(517,208\right.$ and $250 \mathrm{~nm}, \mathrm{TiO}_{2}$ : Ald_R, ST-41 and ST-G1, respectively). It is proposed that storage of photogenerated electrons in noble metal NPs, and thus separation of charge carriers, is the most crucial for samples with a high recombination rate of charge carriers (large titania NPs).

The possibility of electrons storage/mobility was examined by TRMC experiments under UV excitation for silver- and gold-modified titania, and representative results are shown in Fig. 4 (right) and Fig. s3. The surface modification with NPs of noble metals influenced the charge-carrier decay of titania. The TRMC signal is mainly related to the electron mobility. Thus, the observed decrease in the TRMC signal was probably caused by efficient electron trapping by the two metals, decreasing the number of mobile electrons. This influence on the TRMC signal intensity and its decay is related to the photocatalytic activity, as has been reported for titania modified with noble metals $[25,32,33]$. Thus, lower intensity of TRMC signals for metal-modified titania indicating faster electron scavenging by metallic NPs, correlated with higher photocatalytic activities obtained but those samples in comparison with bare titania. 

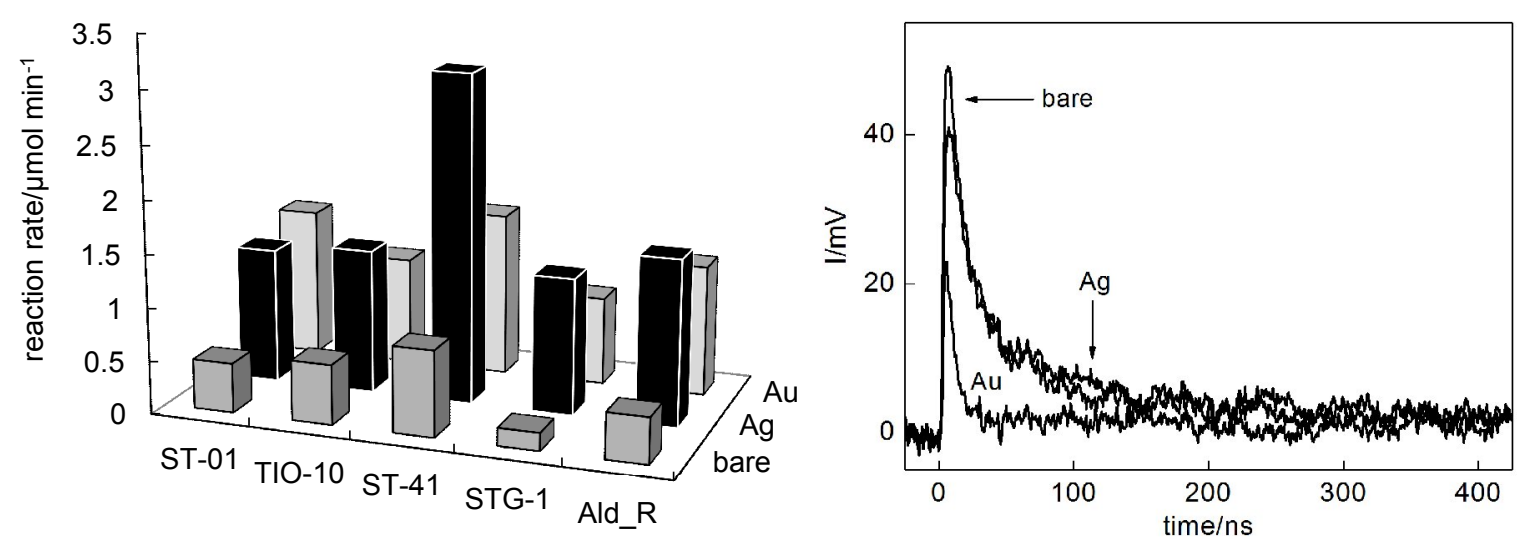

Fig. 4. Left) Acetic acid decomposition under UV/vis irradiation; right) TRMC signals after excitation at 355 $\mathrm{nm}$ for bare, silver- and gold-modified titania: ST-01.

Under visible light irradiation, in contrast to results under UV irradiation, rutile titanias of larger sizes (STG-1 and Ald_R) and fine anatase (ST-01) showed much higher photocatalytic activity than almost inactive anatase titania with large NPs. The reason of poor performance of $\mathrm{Ag} @ \mathrm{TiO}_{2}(\mathrm{ST}-41)$ could be caused by used experimental conditions, i.e., irradiation with wavelengths longer than $450 \mathrm{~nm}$ (to ensure no activity influence by bare titania), and thus larger part of LSPR of silver in this sample was cut off.

To clarify the initial step of photoinduced reaction the action spectrum (AS) experiments were performed for bare and silver-modified titania Ald_R, and obtained data with respective DRS spectrum are shown in Fig. 6. The good correlation between action and absorption spectra confirmed that LSPR of silver NPs was responsible for the photocatalytic activity under visible light irradiation. It should be pointed that though quantum yield under visible light was quite low (0.01-0.1\%), it highly exceeded the activity of gold-modified titanias $(<0.03 \%)$ [14]. In addition, silver-modified titania was active at a broad range of irradiation, i.e., 200-640 nm (proved by AS also in the UV range, data not shown here). Thus, it is proposed that by nano-architecture arrangement, i.e., preparation of various sizes/shapes of silver NPs, it could be possible to obtain silver plasmonic photocatalysts with the ability of working under full solar spectrum. 

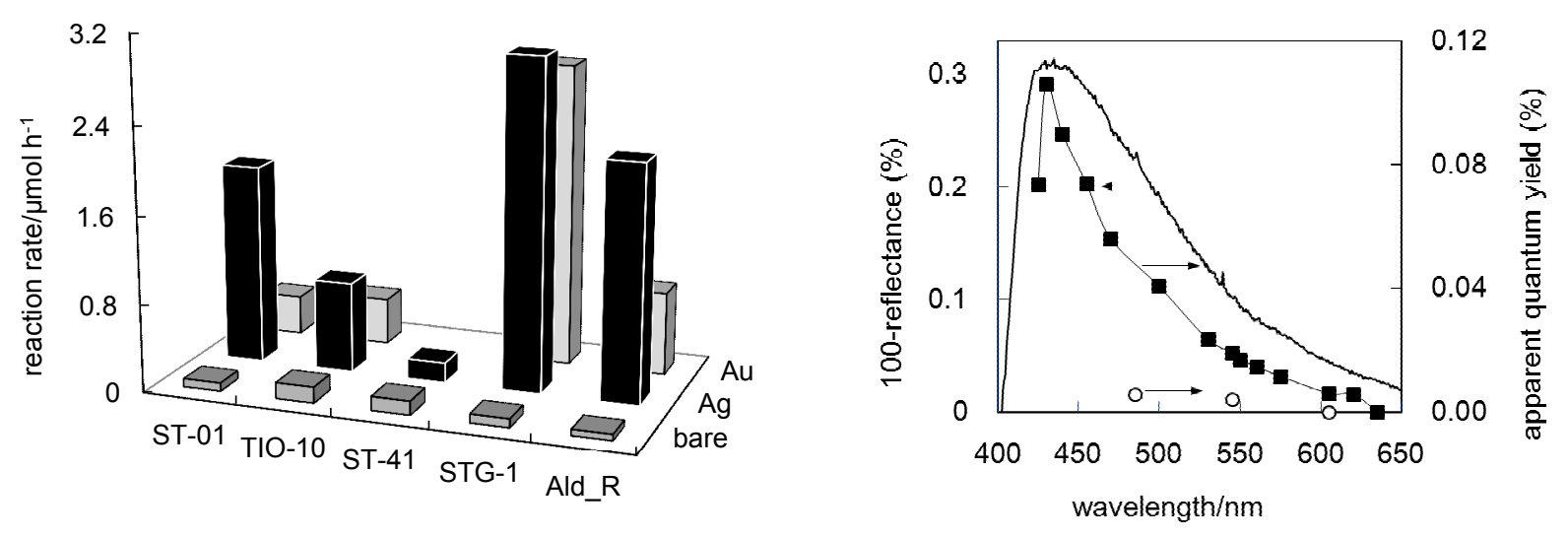

Fig. 5. left) 2-propanol oxidation under visible irradiation on bare and modified titanias ( $2 \mathrm{wt} \% \mathrm{Au}$ or $\mathrm{Ag}$ ); right) action spectra of 2-propanol oxidation on bare (O) and silver-modified (-) titania (Ald_R) with respective DRS spectrum for $\mathrm{Ag} @ \mathrm{TiO}_{2}$.

\subsection{Antibacterial properties}

The method of a small paper disc was unsuccessful since almost no inhibition zones was detected indicating that no active species leaked from the disc. Though the lack of inhibition zones made this method unable to be used for antibacterial properties testing, this observation was positive and indicated that silver-modified titania photocatalysts were stable and could be used as covering material without loss of active species during usage. Then, another method, i.e., application of mixture of suspended titania and bacteria was used and the results are shown in Fig. 6(A-C). The highest level of activity was obtained under UV irradiation. It was reported that reactive oxygen species (ROS) possessing high bactericidal activity were generated on the surface of irradiated titania [16]. It must be mentioned that activity of silver-modified photocatalysts exceeded that of bare ones by two-four orders for all samples (data for bare titanias are not shown here). It is thought that similarly to decomposition of organic compounds, photo-generated electrons were scavenged by silver NPs hindering recombination of charge carriers, and thus more ROS were generated.

Some samples showed activity in the dark, due to antibacterial properties of silver, e.g., the most active was (TIO-6) (fine rutile). On the other hand, some of them were almost inactive, e.g., fine anatase with small silver NPs prepared in 2-propanol: ST-01(IPA) and large rutile: TIO-5. Some samples showed exactly the same activity in the dark and under visible light 
irradiation, e.g., fine (UFR) and large rutile (Ald_R and Ald_R(IPA)) samples, and this indicated that their antibacterial activity was mainly governed by dark antibacterial activity of silver. However, significant enhancement of activity by visible light irradiation was observed for anatase samples of large particles ((Ald_A), Fig. 6B). It should be mentioned that the activity of this sample under visible light irradiation was almost the same as that obtained under UV. The activities of bare titania under visible light irradiation were negligible, and
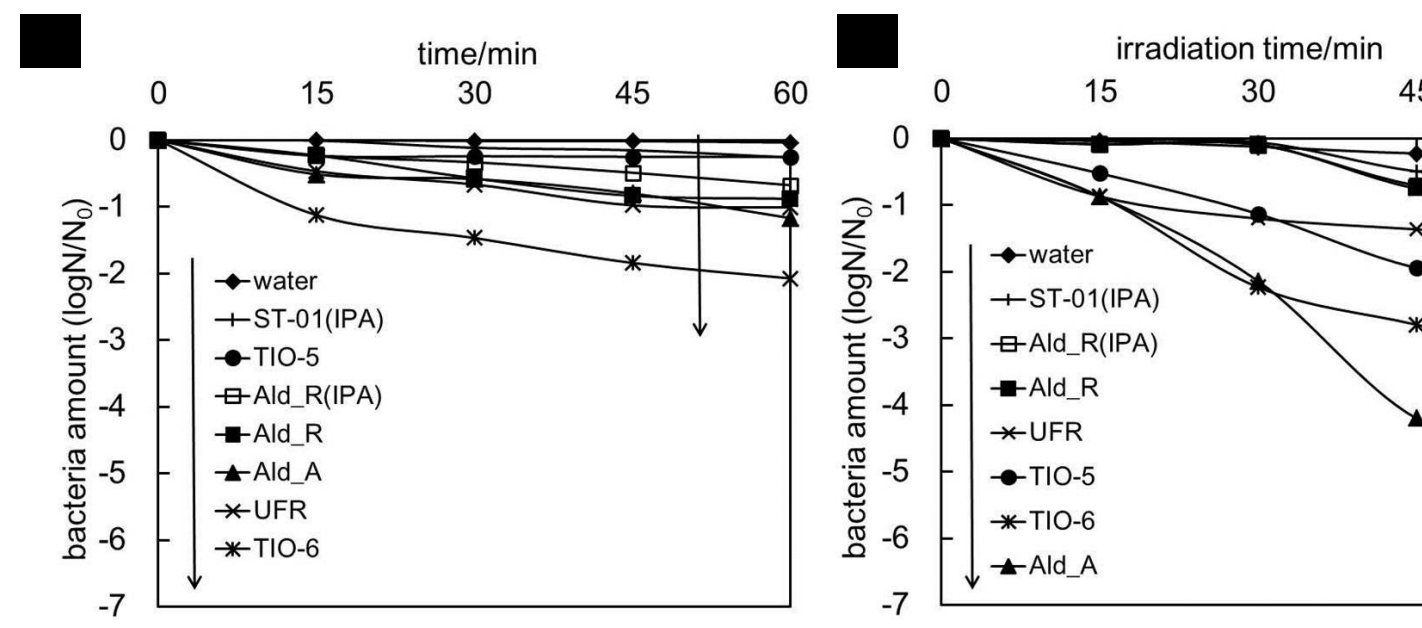

60
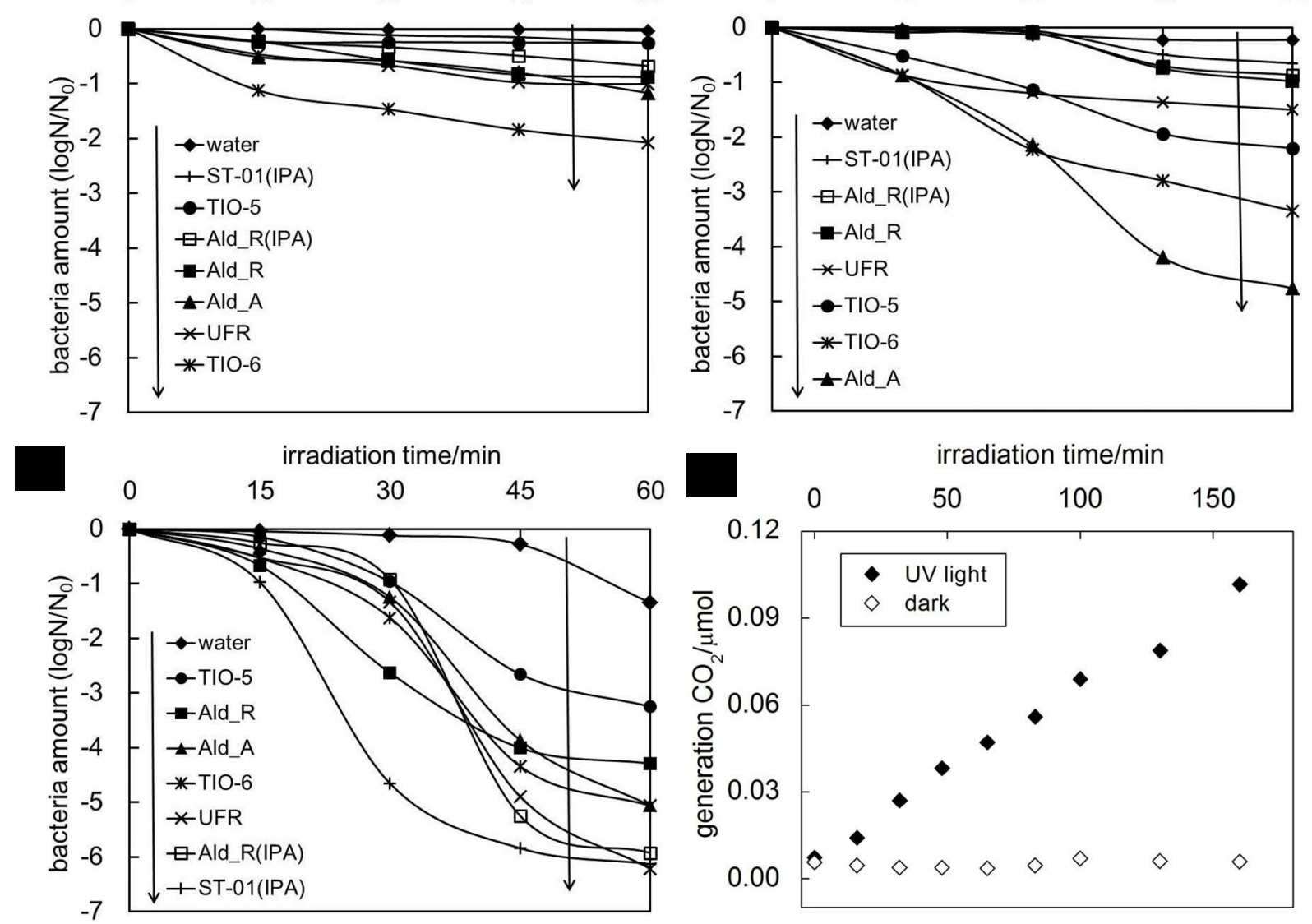

0
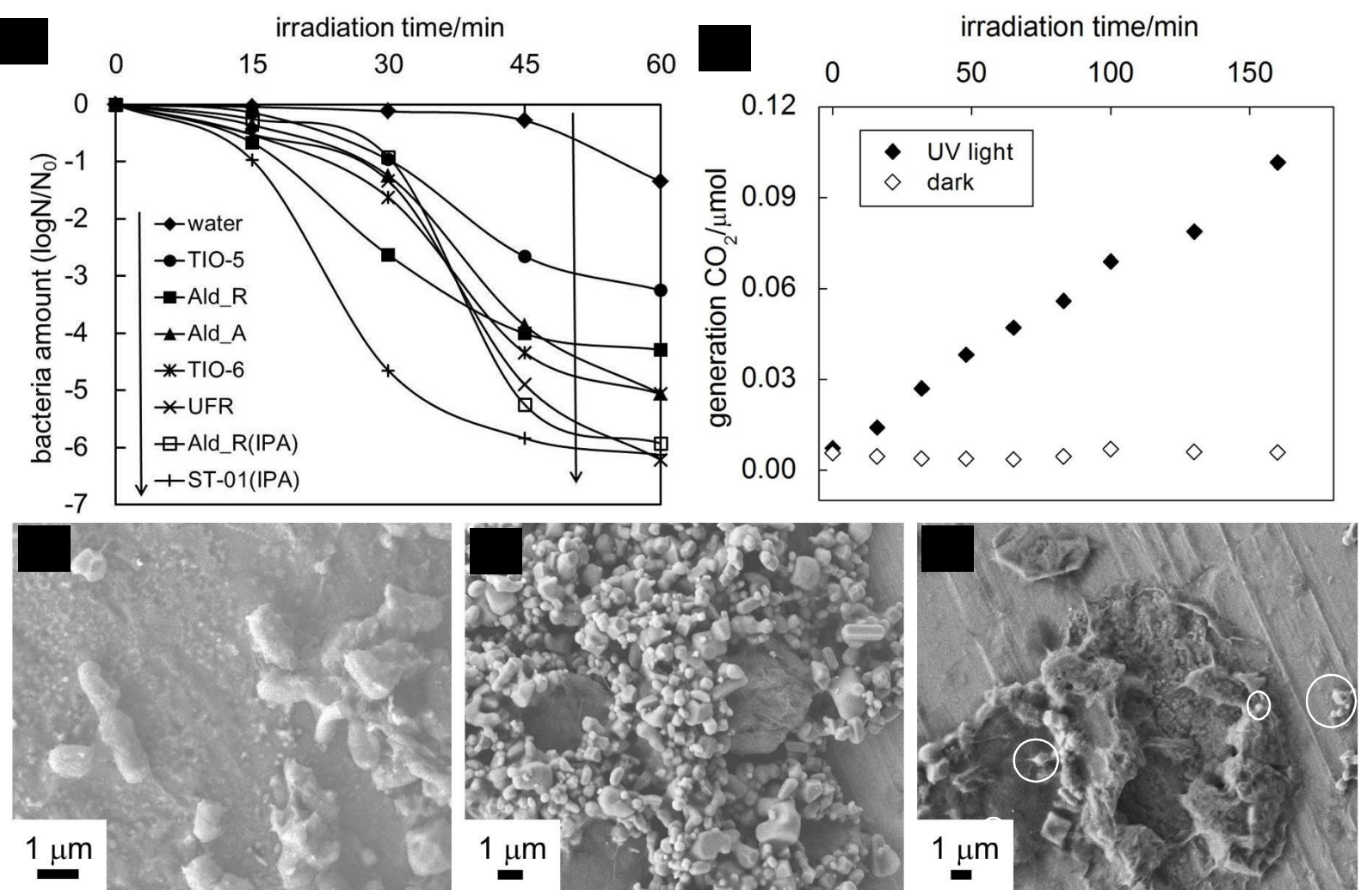

Fig. 6. Antibacterial activity of silver-modified titania: A) in the dark; B) under visible light irradiation ( $>400$ $\mathrm{nm}$ ), C) under UV irradiation, D) mineralization of $E$. coli cells (evolution of $\mathrm{CO}_{2}$ ) under UV irradiation and in the dark, E-G) SEM images showing bacteria cells: E) before irradiation, F) covered with photocatalyst, G) destroyed after UV irradiation (circled NPs of photocatalyst); photocatalyst (D-G): Ag@ $\mathrm{TiO}_{2}$ (TIO-5). 
decomposition of bacteria cells on the most active silver-modified titanias exceeded that on bare ones by three (TIO-6) and four (Ald_A) orders.

To examine the possibilities of bacteria cells complete decomposition, i.e., mineralization, the $\mathrm{CO}_{2}$ evolution during bacteria irradiation was measured, and data for $\mathrm{Ag} @ \mathrm{TiO}_{2}$ (TIO-5) are shown in Fig. 6D. It should be pointed that mineralization of bacteria cells was only possible under irradiation, and $\mathrm{CO}_{2}$ was undetectable during experiments performed in the dark. The SEM images showing bacteria cells before and after decomposition with UV irradiation are shown in Fig. 6(E-G).

To prove cost-effective application of plasmonic photocatalysts the decomposition of bacteria cells under visible light irradiation $(\lambda>450 \mathrm{~nm})$ was investigated and representative results are shown in Fig. 7. In comparison with bare titania (ST41), the addition of silver enhanced antibacterial activity significantly in the dark and under irradiation with visible light. It is clearly observable that even for low-active silver sample, 30 min of irradiation resulted in enhancement of bacteria killing by one order and efficient mineralization of bacteria cells $\left(\mathrm{CO}_{2}\right.$ evolution), in comparison with activity obtained in the dark. Generally, it was observed that during visible light irradiation the amount of carbon dioxide was firstly unchanged and then slowly increased, indicating inhibition of bacteria breathing and subsequent decomposition of bacteria cells, respectively.

The most active samples, i.e., Ag-modified fine anatase (FP6) caused an enhancement of bacteria killing during $2 \mathrm{~h}$ of irradiation by 8 order (data not shown here), in comparison with activity obtained in the dark. One of the most interesting finding indicates that small differences in sizes of deposited metal NPs resulted in large difference in kind and level of antibacterial properties, i.e., silver deposition on the FP6 titania from water resulted in formation of larger NPs of larger antibacterial activity under visible light irradiation than silver deposited from methanol which showed much higher activity under dark conditions [34, 35]. 

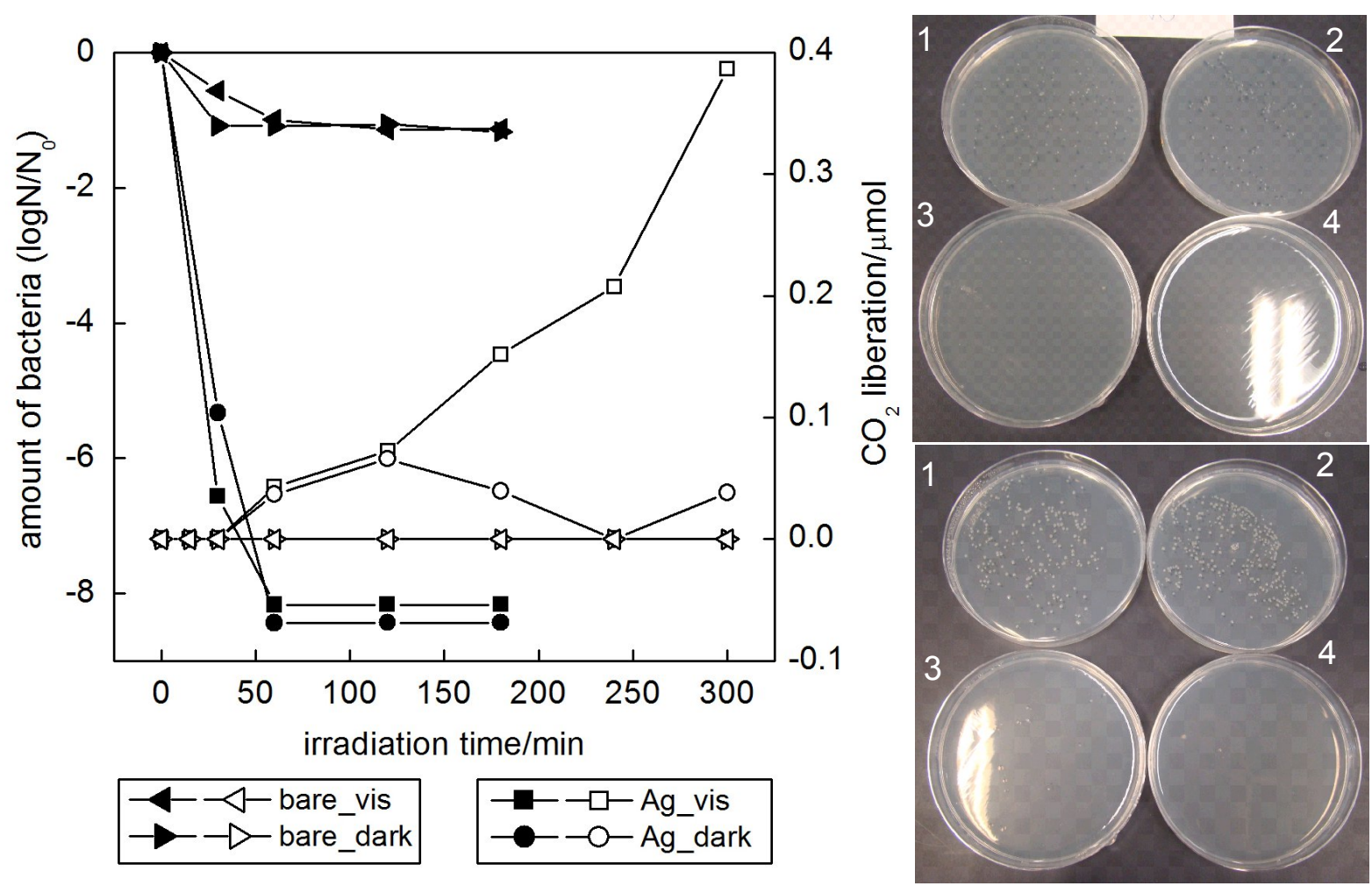

Fig. 7. left) E. coli disappearance shown as amount of bacteria (closed symbols) and evolution of $\mathrm{CO}_{2}$ (open symbols) during decomposition of bacteria cells in the dark and under irradiation with visible light $(>450 \mathrm{~nm})$ on bare and Ag-modified $\mathrm{TiO}_{2}(\mathrm{ST}-41)$; right) photographs of bacteria colony counting (dilution: $10^{-2}$ ) after irradiation with visible light for: 1) $15 \mathrm{~min}$, 2) $30 \mathrm{~min}$, 3) $45 \mathrm{~min}$, 4) $60 \mathrm{~min}$ on Ag-modified titania: Ald_A (top), ST-01(IPA) (bottom).

This suggests that dark antibacterial properties are mainly governed by smaller silver NPs, while photo-antibacterial properties under visible light irradiation are mainly caused by larger silver NPs. It must be pointed that not only size of silver NPs but also its oxidative state could be responsible for antibacterial properties. The participation of silver cations in overall antibacterial properties is currently being studied.

\section{Conclusions}

Plasmonic photocatalysts composed of titania and silver NPs with enhanced photocatalytic activities under UV and/or visible light irradiation were prepared by photodeposition. The level of photocatalytic activities depends on the structural properties of both titania and noble metal NPs and on the reaction system.

It was shown that under UV/vis irradiation the highest level of activity for methanol dehydrogenation was obtained for fine anatase titania with fine silver deposits, indicating that 
for hydrogen evolution reaction the large specific surface area was crucial. On the other hand, during acetic acid decomposition the highest level of activity was obtained by large anatase titania with silver NPs of high size heterogeneity, suggesting that storage of photogenerated electrons in noble metal NPs (suggested by TRMC experiments), and thus separation of charge carriers, was the most crucial for samples with a high recombination rate of charge carriers (large titania NPs).

Under visible light irradiation the highest level of activity was obtained by large rutile titania with highly heterogeneous silver NPs, resulting in a broad LSPR absorption, and thus observable photoactivity at a wide wavelength ranges. Action spectrum analysis proved that LSPR was responsible for the photocatalytic activity in the visible range.

Antibacterial properties of titania photocatalysts were enhanced by visible light irradiation and by modification with NPs of noble metals. The interaction of photocatalyst with light deactivated and decomposed E.coli cells more rapidly. $\mathrm{Ag} @ \mathrm{TiO}_{2}$ with large Ag NPs caused higher activity under irradiation, while those with small Ag NPs exhibited higher activity in the dark. It was shown that bacteria cells could be mineralized also under irradiation with visible light. Therefore, the possibility of a wide range of applications of silver-modified titania for decomposition of both chemical and biological pollutants was proved.

It is expected that soon plasmonic photocatalysts could be applied for environmental purifications.

\section{Acknowledgements}

This research was funded by a grant from Bill \& Melinda Gates Foundation (GCE R8, OPP1060234) and the CONCERT-Japan Joint Call.

\section{References}

[1] M.R. Hoffmann, S.T. Martin, W.Y. Choi, D.W. Bahnemann, Chem. Rev. 95 (1995) 69-96.

[2] R. Asahi, T. Morikawa, T. Ohwaki, K. Aoki, Y. Taga, Science 293 (2001) 269-271.

[3] T. Ohno, M. Akiyoshi, T. Umebayashi, K. Asai, T. Mitsui, M. Matsumura, Appl. Catal. A-Gen. 265 (2004) $115-121$

[4] A. Zaleska, Recent Patents on Engineering 2 (2008) 157-164.

[5] B. Wawrzyniak, A.W. Morawski, 62 (2006) 150-158. 
[6] A. Zaleska, E. Grabowska, J.W. Sobczak, M. Gazda, J. Hupka, Appl Catal B-Environ 89 (2009) 469-475.

[7] D. Mitoraj, H. Kisch, Angew. Chem. Int. Ed. 47 (2008) 9975-9978.

[8] P. Zabek, J. Eberl, H. Kisch, Photochem. Photobiol. Sci. 8 (2009) 264-269.

[9] V. Subramanian, E. Wolf, P.V. Kamat, J. Phys. Chem. B 105 (2001) 11439-11446.

[10] Y. Tian, T. Tatsuma, J. Am. Chem. Soc. 127 (2005) 7632-7637.

[11] P.A. DeSario, J.J. Pietron, D.E. DeVantier, T.H. Brintlinger, R.M. Stroud, D.R. Rolison, Nanoscale 5 (2013) 8073-8083.

[12] E. Kowalska, R. Abe, B. Ohtani, Chem. Commun. (2009) 241-243.

[13] M. Haruta, Catal. Today. 36 (1997) 153-166.

[14] E. Kowalska, O.O.P. Mahaney, R. Abe, B. Ohtani, Phys. Chem. Chem. Phys. 12 (2010) 2344-2355.

[15] A. Zielinska, E. Kowalska, J.W. Sobczak, I. Lacka, M. Gazda, B. Ohtani, J. Hupka, A. Zaleska, Sep. Purif. Technol. 72 (2010) 309-318.

[16] D. Mitoraj, A. Janczyk, M. Strus, H. Kisch, G. Stochel, P.B. Heczko, W. Macyk, 6 (2007) 642-648.

[17] A. Markowska-Szczupak, K. Ulfig, W.A. Morawski, Catal. Today 161 (2011) 249-257.

[18] C. Colbeau-Justin, M. Kunst, D. Huguenin, J. Mater. Sci. 38 (2003) 2429.

[19] G.L. Chiarello, M.H. Aguirre, E. Selli, J. Catal. 273 (2010) 182-190.

[20] A. Sclafani, M.N. Mozzanega, P. Pichat, J. Photochem. Photobiol. A: Chem. 59 (1991) 181-189.

[21] A.L. Linsebigler, G. Lu, J.T. Yates, Jr., Chem. Rev. 95 (1995) 735-758.

[22] P. Pichat, J.M. Herrmann, J. Disdier, H. Courbon, M.N. Mozzanega, Nouv. J. Chim. 5 (1981) 627-636.

[23] A. Sobczynski, A.J. Bard, A. Campion, M.A. Fox, T. Mallouk, S.E. Webber, J.M. White, 91 (1987) 3316-3320.

[24] H.N. Kagalwala, A.B. Maurer, I.N. Mills, S. bernhard, ChemPhysChem 6 (2014) 3018-3026.

[25] E. Kowalska, K. Yoshiiri, Z. Wei, S. Zheng, E. Kastl, H. Remita, S. Rau, B. Ohtani, Appl. Catal. B: Environ. (2015) 10.1016/j.apcatb.2014.1010.1003.

[26] E.I. Isaeva, V.V. Gorbunova, T.B. Boitsova, M.P. Sukontseva, A.Y. Men'shinkova, Y.O. Skurkis, 75 (2005) $1340-1345$.

[27] B.K. Min, W.T. Wallance, D.W. Goodman, Surf. Sci. 600 (2006) L7.

[28] O.O. Prieto-Mahaney, N. Murakami, R. Abe, B. Ohtani, Chem. Lett. 38 (2009) 238-239.

[29] A. Zielińska-Jurek, E. Kowalska, J.W. Sobczak, W. Lisowski, B. Ohtani, A. Zaleska, Appl. Catal. B: Environ. 101 (2011) 504-514.

[30] E. Kowalska, M. Janczarek, L. Rosa, S. Juodkazi, B. Ohtani, Catal. Today 230 (2014) 131-137.

[31] N. Murakami, O.O.P. Mahaney, R. Abe, T. Torimoto, B. Ohtani, J Phys Chem C 111 (2007) 11927-11935.

[32] E. Kowalska, H. Remita, C. Colbeau-Justin, J. Hupka, J. Belloni, J. Phys. Chem. C 112 (2008) 1124-1131.

[33] Z.B. Hai, N. El Kolli, D.B. Uribe, P. Beaunier, M. Jose-Yacaman, J. Vigneron, A. Etcheberry, S. Sorgues, C. Colbeau-Justin, J.F. Chena, H. Remita, J. Mater. Chem. A 1 (2013) 10829-10835.

[34] H. Zabri, I. Gillaizeau, C.A. Bignozzi, S. Caramori, M.F. Charlot, J. Cano-Boquera, F. Odobel, Inorg. Chem. 42 (2003) 6655-6666.

[35] E. Kowalska, Z.S. Wei, B. Karabiyik, M. Janczarek, M. Endo, K. Wang, P. Rokicka, A. Markowska-Szczupak, B. Ohtani, Advances in Science and Technology (2014) accepted. 
Graphical abstract

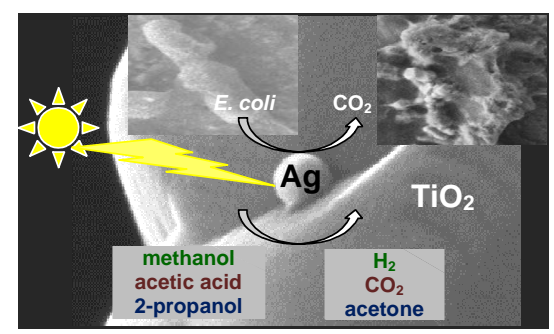

